\title{
Sleep Quality, Anxiety, and Depression Are Associated with Fall Risk Factors in Older Women
}

\author{
Rodrigo Serrano-Checa ${ }^{1}$, Fidel Hita-Contreras ${ }^{1}$ (D) , José Daniel Jiménez-García ${ }^{2,3, *(D),}$ \\ Alexander Achalandabaso-Ochoa ${ }^{1}$ D , Agustín Aibar-Almazán ${ }^{1}$ (D) and Antonio Martínez-Amat ${ }^{1}$ (D) \\ 1 Department of Health Sciences, Faculty of Health Sciences, University of Jaén, 23071 Jaén, Spain; \\ rserranocheca@gmail.com (R.S.-C.); fhita@ujaen.es (F.H.-C.); aaochoa@ujaen.es (A.A.-O.); \\ aaibar@ujaen.es (A.A.-A.); amamat@ujaen.es (A.M.-A.) \\ 2 MOVE-IT Research Group and Department of Physical Education, Faculty of Education Sciences, University \\ of Cádiz, 11003 Cádiz, Spain \\ 3 Biomedical Research and Innovation Institute of Cádiz (INiBICA) Research Unit, Puerta del Mar University \\ Hospital, University of Cádiz, 11009 Cádiz, Spain \\ * Correspondence: josedanieljimenezgarcia@gmail.com; Tel.: +34-956016216
}

Received: 5 May 2020; Accepted: 4 June 2020; Published: 5 June 2020

\begin{abstract}
Gait, dynamic balance, and functional mobility problems are well-known fall risk factors. Furthermore, sleep disturbances, anxiety, and depression are prevalent among older women. This study aimed to analyze the associations of sleep quality, anxiety, and depression with functional mobility, gait speed, and dynamic balance in community-dwelling postmenopausal women aged $\geq$ 60 years. A total of 271 women (69.18 \pm 5.69 years) participated in this study. Functional mobility (Timed Up-and-Go Test), dynamic balance (3-meter tandem walk test), gait speed (OptoGait@optical detection system), sleep quality (Pittsburgh Sleep Quality Index), and anxiety and depression (Hospital Anxiety and Depression Scale) were assessed. Our results showed that poor sleep efficiency and the use of sleeping medication were related to decreased gait speed $\left(R^{2}=0.072\right)$. Poor functional mobility was linked to depression and the use of sleeping medication $\left(R^{2}=0.159\right)$. Additionally, increased symptoms of anxiety and depression were associated with worsened dynamic balance $\left(R^{2}=0.127\right)$. In conclusion, poorer sleep quality is associated with slower gait speed and reduced functional mobility, which is also related, along with impaired dynamic balance, to higher levels of anxiety and depression.
\end{abstract}

Keywords: sleep quality; anxiety; depression; gait speed; functionality; dynamic balance

\section{Introduction}

Sleep disturbances, anxiety, and depression are prevalent among postmenopausal women [1,2], who in addition are more commonly affected by sleep difficulties than younger women [3]. Furthermore, during the post-menopausal stage between $40 \%$ and $60 \%$ of women are affected by poor sleep and insomnia [4]. Poor sleep quality and quality of life are associated with physical and psychological problems [5,6].

As far as psychological problems are concerned, anxiety and depression are very common and debilitating diseases with a considerable impact on the economic, social, and personal life of those affected $[7,8]$. Women are at higher risk of depressive disorder than men [9]. This is usually related to certain stressors (i.e., familial, economic, social, sexual, and health-related) that seem to aggravate mood disorders in this population [10-13]. Menopausal status is also associated with an increased risk of mood disorders. Among women without a history of depression or anxiety, and compared with pre-menopausal individuals, the peri-and postmenopausal stages are associated with an increased risk for symptoms of anxiety [14]. 
Aging is generally associated with gait and balance disorders, neuromuscular impairment, and lower levels of mobility, and therefore with an increased risk of falls and fractures [15]. Falls and fall-related injuries are one of the main health problems affecting postmenopausal women [16]. Due to the aging process, elderly and postmenopausal individuals tend to reduce their physical activity levels and become more dependent on external help. Falls are the result of several multivariate risk factors which are frequently classified as either extrinsic or intrinsic. The later are related to functional and health status, with gait instability and balance deficit being some of the most common intrinsic risk factors in older people [17]. Gait speed has repeatedly been shown to be a reliable tool in predicting falls and discriminating between fallers and non-fallers [18]. Decreased gait speed [19], poor mobility, and dynamic balance [20] have been linked to an increased risk of falling among community-dwelling older adults.

This study aims to analyze the associations of sleep quality, anxiety, and depression with functional mobility, gait speed, and dynamic balance in community-dwelling postmenopausal women aged 60 years and older. We hypothesize that postmenopausal individuals displaying signs of better sleep quality and lower levels of anxiety and depression have faster gait speed as well as better functional mobility and dynamic balance.

\section{Materials and Methods}

\subsection{Study Participants}

This cross-sectional study involved community-dwelling women who were recruited through several associations of postmenopausal women in the Eastern Andalusia region (Jaén and Málaga), and using municipal records, local media, and social networks. A total of 271 older women $(69.18 \pm 5.69$ years) participated in this study (Figure 1). To be included, subjects had to be women aged 60 years and over and able to understand the instructions, programs, and protocols involved in the study. Exclusion criteria were conditions that contraindicated the performance of physical tests, diseases that could alter balance and functional activity (such as auditory or vestibular alterations), central or peripheral neurological disorders, and serious psychiatric or somatic diseases. Firstly, we informed subjects about the main purpose and the reasons for conducting the study. Secondly, we briefly explained its associated risks. All procedures were anonymous. A written informed consent form was obtained from each participant before enrollment. This study was approved by the local Human Ethics Committee (OCT.18/4.PRY) and was conducted in accordance with the Declaration of Helsinki, good clinical practices, and applicable laws and regulations.

\subsection{Outcomes}

Outcomes measures were sociodemographic and anthropometric data, sleep quality, anxiety and depression, functional mobility, dynamic balance and gait speed.

\subsubsection{Sociodemographic and Anthropometric Data}

Demographic data such as age, years of menopause, educational, marital, and occupational status, and smoking habits were collected by well-trained interviewers. Body mass index (BMI) was obtained by dividing the women's weight $(\mathrm{kg})$ by their height squared $\left(\mathrm{m}^{2}\right)$. A $100 \mathrm{~g}-130 \mathrm{~kg}$ precision digital weight scale (Tefal, Barcelona, Spain) and T201-T4 Asimed adult height scale (Asimed, T201-T4, Barcelona, Spain) were employed for weight and height assessment. A BMI $\geq 30 \mathrm{~kg} / \mathrm{m}^{2}$ indicated obesity [21]. Waist circumference was measured using a $1.5 \mathrm{~m}$ flexible tape (Lufkin, W606PM, MD, USA) at the midpoint between the lowest rib and the iliac crest, with participants in the standing position. A waist circumference $\geq 88 \mathrm{~cm}$ was taken as an indicator of abdominal obesity [21]. 


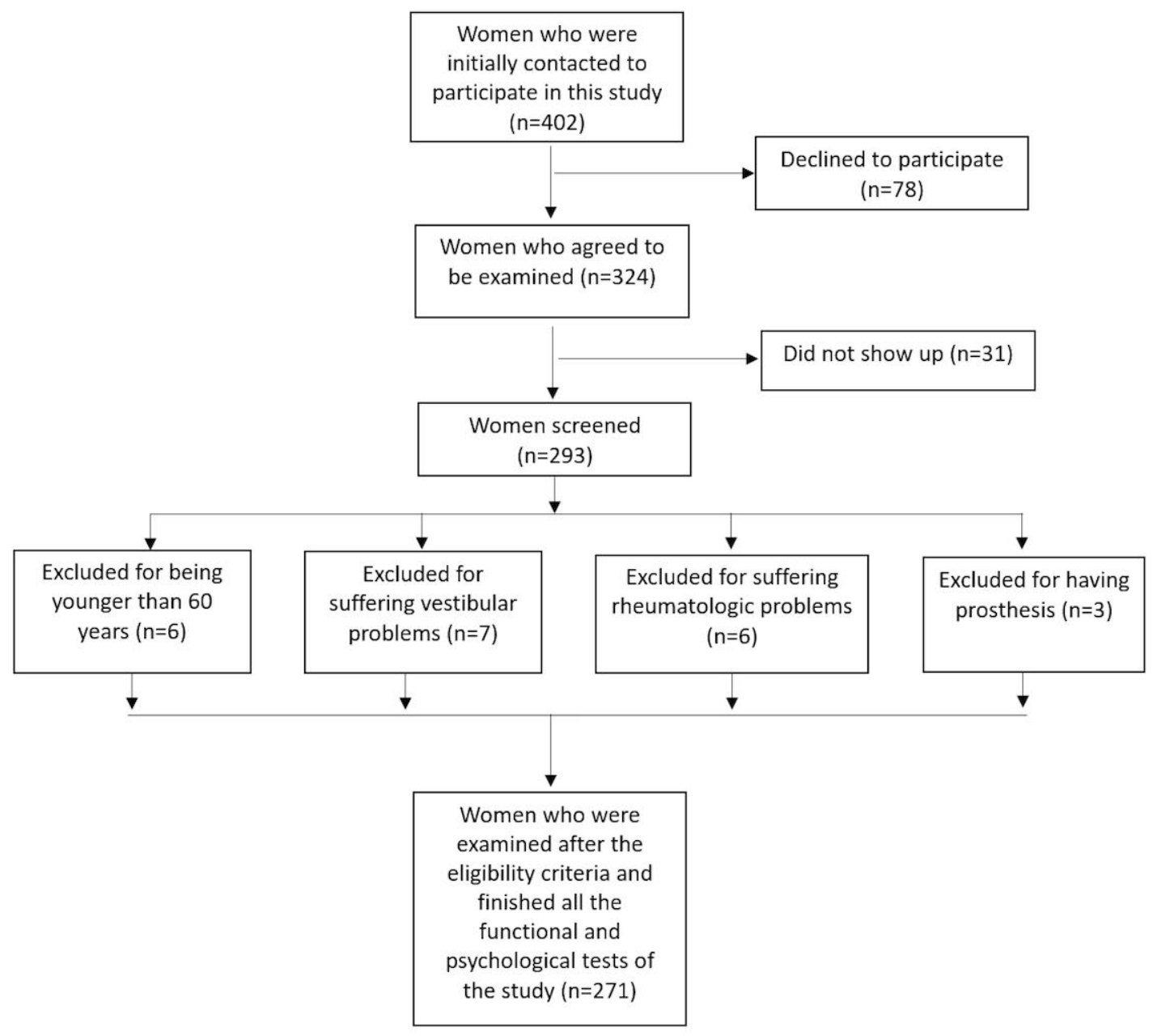

Figure 1. Flow chart of the study participants.

\subsubsection{Sleep Quality}

In order to assess sleep quality, the Pittsburgh Sleep Quality Index (PSQI) [22,23] was used. This questionnaire includes 19 self-rated questions and 5 questions to be answered by bedmates or roommates (these last only being used to gather clinical information). The 19 self-rated questions generate a total score and 7 domain scores (on a scale of 0 to 3 , with higher scores indicating poorer sleep quality): C1, sleep quality; $\mathrm{C} 2$, sleep latency; $\mathrm{C} 3$, sleep duration; $\mathrm{C} 4$, sleep efficiency; 5, sleep disturbances; $\mathrm{C} 6$, use of sleep medication; $\mathrm{C}$, daytime dysfunction. In turn, these 7 scores range from 0 to 21 , with a total score $>5$ indicating poor sleep quality [22,24].

\subsubsection{Anxiety and Depression}

The Hospital Anxiety and Depression Scale (HADS) $[25,26]$ was developed to assess anxiety and depression in the general population. A total of 14 items are equally divided into an anxiety subscale of 7 items and a depression subscale of the remaining other 7 items [27]. Scores range from 0-21, where higher values indicate more severe symptoms. A cut-off of $\geq 11$ was used to identify cases of both anxiety and depression.

\subsubsection{Functional Mobility}

The Timed Up-and-Go test (TUG) is a simple, valid, and reliable method to assess functional mobility [28], which has already been used in elderly women [29]. It is based on everyday activities and requires standing from a chair, walking three meters, turning around, and sitting down again [30]. 
The time required by the subject to complete this task is recorded. Longer TUG test times indicate poorer functional mobility. It has been shown that a time $<12 \mathrm{~s}$ in the TUG test is an indication of low risk of falling [31].

\subsubsection{Dynamic Balance}

The 3-meter Timed Tandem Walk (3MTW) Test is a functional tool used to evaluate mobility and dynamic balance. The test takes place on a marked, 3-meter long flat surface. The patient is requested to walk this distance at a comfortable pace. The time starts with the foot on the starting line and ends when the foot crosses the finishing line. Subjects walked on a marked line, stepping heel to toe, and wearing casual footwear [32]. A time $>4.5 \mathrm{~s}$ is generally considered a likely indicator of having reported falling [33].

\subsubsection{Gait Speed}

The OptoGait gait analysis system (Microgate Italy, Bolzano-Bozen, Italy), a device consisting of an opto-electrical detection system, was employed for gait analysis $(\mathrm{m} / \mathrm{s})$. The transmitter bar has 96 light-emitting diodes (LEDs) that communicate in the infrared spectrum. The receiver bar, which is positioned opposite it, has the same number of LEDs. The transmitter and receiver bars of the OptoGait were installed on both sides of a treadmill. To assess gait speed, participants were asked to walk for 30 $\mathrm{s}$, while gait speed information was collected by the photocell system. Two familiarization and five experimental trials were performed, with a one-minute rest interval between trials. Gait speed values $<1.0 \mathrm{~m} / \mathrm{s}$ are associated with several fall risk factors among community-dwelling elderly people [19].

\subsection{Sample Size Calculation}

For sample size calculation at least 20 subjects per event were required in the multivariate lineal regression model [34]. Thirteen possible events were used: 7 PSQI domains, its total score, depression and anxiety scores, as well as age, BMI, and waist circumference. Therefore 260 participants were required for this analysis. The final number of participants was 271 .

\subsection{Data Analysis}

Continuous variables were described using means and standard deviations, whereas categorical variables were described using frequencies and percentages. The Kolmogorov-Smirnov test was used to assess the normal distribution of variables. A bivariate correlation analysis was used to assess the possible individual ways that sleep quality, anxiety, and depression as independent variables, as well as other covariables such as age, BMI, and waist circumference, are associated with gait speed, functional mobility, and dynamic balance. In order to explore the independent associations between variables a multivariate linear regression model was employed, as well as a stepwise method for introducing variables into the model. Gait speed, functional mobility, and dynamic balance were individually introduced as dependent variables in separate models. We first looked into the bivariate correlation coefficients and variables with significant associations $(p<0.05)$ were included in the multivariate linear regression. Adjusted- $\mathrm{R}^{2}$ was used to calculate the effect size coefficient of multiple determination in the linear models. $\mathrm{R}^{2}$ can be can be considered insignificant when $<0.02$, small if between 0.02 and 0.15 , medium if between 0.15 and 0.35 , and large if $>0.35$ [35]. A 95\% confidence level was used $(p<0.05)$. Data management and analysis were carried out using the SPSS statistical package for the social sciences for Windows (SPSS Inc., Chicago, IL, USA).

\section{Results}

Table 1 displays the descriptive data for the participants. A total of 271 women $(69.18 \pm 5.69$ years $)$ took part in the present study. Most participants were married or living with a partner $(59.04 \%)$, had primary education or less $(81.55 \%)$, and were retired $(81.54 \%)$. Mean BMI was $29.96 \pm 4.22 \mathrm{~kg} / \mathrm{m}^{2}$, 
which indicates overweight bordering on obesity, and the mean waist circumference value was $94.54 \pm$ $9.59 \mathrm{~cm}$, which indicates abdominal obesity. Scores for HADS anxiety and depression were $6.86 \pm 4.21$ and $5.58 \pm 3.59$ respectively. Regarding PSQI, sleep disturbances was the most affected domain, and its total score was $7.57 \pm 4.31$. Regarding the dependent variables, time values for the TUG and the $3 \mathrm{MWT}$ were $8.35 \pm 2.08 \mathrm{~s}$ and $2.58 \pm 0.77 \mathrm{~s}$ respectively, while gait speed was $1.16 \pm 0.27 \mathrm{~m} / \mathrm{s}$, which indicates a low risk of falls.

Table 1. Descriptive data of the sample $(n=271)$.

\begin{tabular}{|c|c|c|c|}
\hline \multirow{2}{*}{\multicolumn{2}{|c|}{ Characteristics }} & \multicolumn{2}{|c|}{ Values } \\
\hline & & Mean & SD \\
\hline \multicolumn{2}{|c|}{ Age (years) } & 69.18 & 5.69 \\
\hline \multicolumn{2}{|c|}{ Time since menopause (years) } & 20.41 & 8.34 \\
\hline \multicolumn{2}{|c|}{ Waist circumference $(\mathrm{cm})$} & 94.54 & 9.59 \\
\hline \multicolumn{2}{|c|}{ BMI $\left(\mathrm{kg} / \mathrm{m}^{2}\right)$} & 29.96 & 4.22 \\
\hline & & Frequency & Percentage \\
\hline \multirow{3}{*}{ Occupational status } & Retired & 221 & 81.54 \\
\hline & Working & 20 & 7.38 \\
\hline & Unemployed & 30 & 11.07 \\
\hline \multirow{3}{*}{ Marital status } & Single & 3 & 1.11 \\
\hline & Married/cohabiting & 160 & 59.04 \\
\hline & Separated/divorced/Widowed & 108 & 39.85 \\
\hline \multirow{4}{*}{ Educational status } & No formal education & 83 & 30.63 \\
\hline & Primary education & 138 & 50.92 \\
\hline & Secondary education & 34 & 12.55 \\
\hline & University & 16 & 5.90 \\
\hline \multirow{2}{*}{ Smoker } & Yes & 11 & 4.06 \\
\hline & No & 260 & 95.94 \\
\hline & & Mean & SD \\
\hline \multicolumn{2}{|c|}{ HADS Anxiety score } & 6.86 & 4.21 \\
\hline \multicolumn{2}{|c|}{ HADS Depression score } & 5.58 & 3.59 \\
\hline \multirow{8}{*}{ PSQI } & Sleep quality & 1.14 & 0.83 \\
\hline & Sleep latency & 1.38 & 1.02 \\
\hline & Sleep duration & 0.87 & 0.92 \\
\hline & Sleep efficiency & 0.94 & 1.13 \\
\hline & Sleep disturbances & 1.56 & 0.72 \\
\hline & Use of sleeping medication & 1.02 & 1.33 \\
\hline & Daytime dysfunction & 0.65 & 0.69 \\
\hline & Total score & 7.57 & 4.31 \\
\hline \multicolumn{2}{|c|}{ Gait speed (m/s) } & 1.16 & 0.27 \\
\hline \multicolumn{2}{|c|}{ TUG test (s) } & 8.35 & 2.08 \\
\hline \multicolumn{2}{|c|}{$3 \mathrm{MTW}(\mathrm{s})$} & 2.58 & 0.77 \\
\hline
\end{tabular}

BMI: Body Mass Index. HADS: Hospital Anxiety and Depression Scale. PSQI: Pittsburgh Sleep Scale Index. TUG: Timed Up and Go test. 3MTW: 3-Meter Timed Tandem Walk Test. SD: Standard Deviation.

The bivariate analysis (Table 2) showed that all the dependent variables considered in the present study (i.e., gait speed, TUG test, and 3MTW) significantly correlated with both HADS anxiety and depression scores, as well as with the PSQI total score. When analyzing gait speed, significant correlations were also observed with all the domains of the PSQI except for sleep disturbances and daytime dysfunction (gait speed), and sleep efficiency and sleep disturbances (functional mobility). In regard to functional mobility, lower time values in the 3MTW test were correlated with poorer sleep quality, sleep latency, and daytime dysfunction. As for the covariables included in the analysis, higher time values in the 3MTW test were associated with higher values in all three of them, while greater 
BMI and waist circumference were linked to longer time in completing the TUG test, and only waist circumference was negatively related to gait speed.

Table 2. Pearson's correlations between variables analyzed in this study.

\begin{tabular}{|c|c|c|c|}
\hline Variable & Gait Speed (m/s) & TUG Test (s) & 3MTW (s) \\
\hline Sleep quality & $-0.220 * *$ & $0.171^{* *}$ & $0.179^{* *}$ \\
\hline Sleep latency & $-0.197 * *$ & $0.162^{* *}$ & $0.161^{* *}$ \\
\hline Sleep duration & $-0.133 *$ & -0.020 & -0.009 \\
\hline Sleep efficiency & $-0.250^{* *}$ & 0.019 & 0.051 \\
\hline Sleep disturbances & -0.044 & $0.188^{* *}$ & 0.099 \\
\hline Use of sleeping medication & $-0.170 * *$ & $0.198^{* *}$ & 0.110 \\
\hline Daytime dysfunction & -0.031 & $0.265^{* *}$ & $0.122 *$ \\
\hline Total score & $-0.248^{* *}$ & $0.205^{* *}$ & $0.154 *$ \\
\hline HADS Anxiety score & $-0.133 *$ & $0.318^{* *}$ & $0.270 * *$ \\
\hline HADS Depression score & $-0.135 *$ & $0.294^{* *}$ & $0.283^{* *}$ \\
\hline Age (years) & -0.018 & 0.073 & $0.213^{* *}$ \\
\hline $\mathrm{BMI}\left(\mathrm{kg} / \mathrm{m}^{2}\right)$ & -0.074 & $0.202^{* *}$ & $0.178^{* *}$ \\
\hline Waist circumference $(\mathrm{cm})$ & $-0.220 * *$ & $0.171^{* *}$ & $0.179 * *$ \\
\hline
\end{tabular}

TUG: Timed Up and Go test. 3MTW: 3-Meter Timed Tandem Walk Test. PSQI: Pittsburgh Sleep Scale Index. HADS: Hospital Anxiety and Depression Scale. BMI: Body Mass Index. ${ }^{*} p<0.05 .{ }^{* *} p<0.01$.

The multivariate linear regression analysis (Table 3) showed several independent associations with the different fall risk factors analyzed in this study. Poor sleep quality was linked to sleep efficiency, and the use of use of sleeping medication was associated with decreased gait speed $\left(\mathrm{R}^{2}=0.072\right)$. Increased age, depression symptoms, waist circumference, and the use of sleeping medication were related to poorer functional mobility $\left(\mathrm{R}^{2}=0.159\right)$. Lastly, the multivariate analysis revealed associations between worse dynamic balance and higher levels of anxiety and depression, and age $\left(\mathrm{R}^{2}=0.127\right)$.

Table 3. Multivariate linear regression analyses for factors associated with gait parameters, functional mobility, and dynamic balance.

\begin{tabular}{cccccccc}
\hline & Variable & $\boldsymbol{B}$ & $\boldsymbol{\beta}$ & $\boldsymbol{t}$ & \multicolumn{2}{c}{$\mathbf{9 5 \%} \mathbf{C I}$} & \multicolumn{1}{c}{$\boldsymbol{p}$-Value } \\
\hline $\begin{array}{c}\text { Gait speed } \\
(\mathrm{m} / \mathrm{s})\end{array}$ & Sleep efficiency & -0.05 & -0.23 & -3.79 & -0.08 & -0.03 & 0.000 \\
& Use of sleeping medication & -0.03 & -0.13 & -2.15 & -0.05 & 0.00 & 0.032 \\
\hline \multirow{3}{*}{ TUG test (s) } & Age & 0.10 & 0.29 & 5.04 & 0.06 & 0.15 & 0.000 \\
& Depression & 0.10 & 0.18 & 3.05 & 0.04 & 0.17 & 0.003 \\
& Waist circumference & 0.03 & 0.14 & 2.47 & 0.01 & 0.06 & 0.014 \\
& Use of sleeping medication & 0.21 & 0.13 & 2.29 & 0.03 & 0.39 & 0.023 \\
\hline \multirow{3}{*}{ 3MTW (s) } & Depression & 0.03 & 0.14 & 1.93 & 0.00 & 0.06 & 0.054 \\
& Age & 0.03 & 0.21 & 3.65 & 0.01 & 0.04 & 0.000 \\
& Anxiety & 0.04 & 0.19 & 2.57 & 0.01 & 0.06 & 0.011 \\
\hline
\end{tabular}

$B$ : unstandardized coefficient. $\beta$ : standardized coefficient. CI: confidence interval. TUG: Timed Up and Go test. 3MTW: 3-Meter Timed Tandem Walk Test.

\section{Discussion}

The main purpose of this study was to explore the associations of sleep quality, anxiety, and depression with fall risk factors. Our results showed that elderly women are at risk of falling when they have poor sleep quality, specifically when they have a poor sleep efficiency and are administered high doses of sleep medication, as this is associated with decreases in gait speed. Furthermore, when poor sleep efficiency and high levels of depression are present, an increased risk of falling has been observed due to reduced functional mobility. Finally, when anxiety and depression are present, the risk of falling increases, since they have been inversely associated with dynamic balance. This implies that psychological factors may play an important role in predicting the risk of falls among elderly 
women. These results contribute to the existing knowledge of the importance of sleep quality, anxiety, and depression as fall risk factors in an elderly women population [36-38].

Recently, interest has grown regarding the identification of fall risks among the elderly, particularly concerning physical factors and their potential influence on such risks. Poor TUG test performance, slower speed gait, and poor dynamic balance have been linked to being at risk of falling [19,31,32]. In addition, it has been suggested that non-restorative sleep can, in the long term, impair motor control and cognitive functions in adult and elderly populations [39]. Besides, psychological distress such as anxiety or depression have been linked to increased difficulty in performing both cognitive and motor coordination tasks [40].

Our results show that gait speed, TUG test results, and dynamic balance have a significant correlation with PSQI scores, which illustrates the link between sleep quality and motor function. For gait speed we found a correlation with sleep quality measured through PSQI, which shows that elderly women with poorer sleep quality have reduced gait speed. This finding is in agreement with those of Kurose et al. [41], who obtained similar results for 102 elderly participants with cardiovascular disease concerning sleep quality and gait speed. In addition, we found a correlation between gait speed and sleep quality, where elderly women with poorer sleep quality needed more time to complete the task. This is in accordance with Del Brutto et al. [42] who showed that higher scores in sleep quality (measured by PSQI) were significantly associated with frailty in a community-dwelling population. In contrast to our findings, a study from the year 2017 showed that, after adjusting for sex in 898 elderly individuals (506 women), longer sleep duration was associated with a decrease in gait speed [43]. Finally, a relation between sleep quality and dynamic balance was found, meaning that among subjects in our sample poor sleep quality is linked to dynamic imbalance. This association between sleep quality and dynamic balance could be explained by the fact that a restorative sleep has been proved to be necessary to learn, acquire, and maintain motor behaviors [44]. Thus, people under non-restorative sleep have difficulties in learning new motor skills and even show a tendency to worsen their performance in that regard. This trend has been observed to be stronger among the elderly. Additionally, non-restorative sleep has been shown to impair motor control, which could lead to increased coordination difficulties, affecting the ability to walk and turn around fluently. Despite the relationship found in our study between sleep quality and functional mobility, it seems that other factors, such as the amount of sleep time, may play a significant role, as suggested by a study carried out in an elderly population [45]. Therefore, sleeping longer or shorter than 7-8 h has been correlated with an increase in the time required to complete the TUG test [43]. This could be explained by a decrease in the time that elderly individuals are active, which may then contribute to lower skeletal muscle mass levels and consequently to a decrease in muscle strength [46].

Our results showed that gait speed, TUG test scores, and dynamic balance have a significant correlation with both HADS scores. This highlights the need to also evaluate psychological factors such as anxiety and depression and not just functional factors in order to obtain a correct assessment of the risk of falling among the elderly. This is in agreement with recent studies $[47,48]$ which have also reported significant positive associations between TUG test scores and depression and anxiety. While the reason for psychological distress impairing functional mobility may lie in the decreased ability to focus on the task at hand, it has also been suggested that those who are afraid of falling may experience anxiety [47], which could lead to a vicious circle of depression and self-imposed restrictions in the performance of daily activities.

In addition to functional and psychological factors, our results showed that physical factors such as age, BMI, and waist circumference are related to the risk of falling. Therefore, having a larger waist circumference negatively affects gait speed, and having higher values on any of these three physical factors negatively affects dynamic balance. Others researchers have obtained similar results $[49,50]$. A possible explanation for these results may be linked to an increase in sarcopenia or sarcopenic obesity, which has been associated with older age and obesity, and has been shown to have a negative impact on the risk of falls [51]. 
Finally, the multivariate linear regression analysis showed associations for gait speed, functional mobility, and dynamic balance. Gait speed was found to be negatively affected by poor sleep quality as it relates to sleep efficiency and the use of sleeping medication. Functional mobility was found to be negatively affected by older age, depression symptoms, increased waist circumference, and the use of sleeping medication. Dynamic balance was found to be negatively affected by older age and having higher levels of anxiety or depression. Taken together, when evaluating risks or when planning a treatment aimed at reducing fall risks in a population of elderly women, our scope should not be limited to physical function but include psychological and physical aspects as well given that our analyses show them to be closely linked to the risk of falls.

This study has some limitations that must be acknowledged. Its cross-sectional design does not allow for determining causal links between sleep quality, anxiety, and depression and the fall risk factors we have analyzed, and therefore any result should be interpreted with caution. In addition, although the PSQI is a validated and widely-used questionnaire to assess sleep quality, we did not employ objective measurement tools such as polysomnography or accelerometery.

\section{Conclusions}

In conclusion, the findings of the present study suggest that, among community-dwelling postmenopausal women aged $\geq 60$ years, sleep quality, anxiety, and depression were independently associated with three important fall risk factors such as gait speed, functional mobility, and dynamic balance. Particularly, our results showed an association of poor sleep efficiency and the use of sleeping medication with decreased gait speed; of worse functional mobility with depression and the use of sleeping medication; and lastly, of greater levels of anxiety and depression symptoms with poor dynamic balance. These findings allow us to suggest that gathering information about sleep quality, anxiety, and depression may be of help when considering fall risks in community-dwelling postmenopausal women aged 60 years and over. Future intervention studies should probably use objective measurements in order to corroborate and expand on our findings.

Author Contributions: Conceptualization: R.S.-C. and A.M.-A.; methodology: J.D.J.-G. and F.H.-C.; formal analysis: F.H.-C.; supervision: A.M.-A., A.A.-O. and A.A.-A.; writing-original draft preparation: R.S.-C., J.D.J.-G. and F.H.-C.; writing-review and editing: A.M.-A., A.A.-O. and A.A.-A.; funding acquisition: A.M.-A. and F.H.-C. All authors have read and agreed to the published version of the manuscript.

Funding: This research was supported by the project 1260735, integrated into the 2014-2020 Operational Programme FEDER in Andalusia.

Conflicts of Interest: The authors declare no conflicts of interest.

\section{References}

1. Terauchi, M.; Hiramitsu, S.; Akiyoshi, M.; Owa, Y.; Kato, K.; Obayashi, S.; Matsushima, E.; Kubota, T. Associations between anxiety, depression and insomnia in peri-and post-menopausal women. Maturitas 2012, 72, 61-65. [CrossRef]

2. Llaneza, P.; García-Portilla, M.P.; Llaneza-Suárez, D.; Armott, B.; Pérez-López, F.R. Depressive disorders and the menopause transition. Maturitas 2012, 71, 120-130. [CrossRef]

3. Naufel, M.F.; Frange, C.; Andersen, M.L.; Girão, M.J.B.C.; Tufik, S.; Beraldi Ribeiro, E.; Hachul, H. Association between obesity and sleep disorders in postmenopausal women. Menopause 2018, 25, 139-144. [CrossRef] [PubMed]

4. Shaver, J.L.; Woods, N.F. Sleep and menopause: A narrative review. Menopause 2015, 22, 899-915. [CrossRef] [PubMed]

5. Goldman, S.E.; Stone, K.L.; Ancoli-Israel, S.; Blackwell, T.; Ewing, S.K.; Boudreau, R.; Cauley, J.A.; Newman, A.B. Poor sleep is associated with poorer physical performance and greater functional limitations in older women. Sleep 2007, 30, 1317-1324. [CrossRef] [PubMed] 
6. Hita-Contreras, F.; Zagalaz-Anula, N.; Martínez-Amat, A.; Cruz-Díaz, D.; Sánchez-Montesinos, I.; Aibar-Almazán, A.; Lomas-Vega, R. Sleep quality and its association with postural stability and fear of falling among Spanish postmenopausal women. Menopause 2018, 25, 62-69. [CrossRef]

7. Wells, K.B.; Stewart, A.; Hays, R.D.; Burnam, M.A.; Rogers, W.; Daniels, M.; Berry, S.; Greenfield, S.; Ware, J. The functioning and well-being of depressed patients: Results from the Medical Outcomes Study. JAMA 1989, 262, 914-919. [CrossRef]

8. Kouzis, A.C.; Eaton, W.W. Emotional disability days: Prevalence and predictors. Am. J. Public Health 1994, 84, 1304-1307. [CrossRef]

9. Kessler, R.C.; McGonagle, K.A.; Swartz, M.; Blazer, D.G.; Nelson, C.B. Sex and depression in the National Comorbidity Survey I: Lifetime prevalence, chronicity and recurrence. J. Affect Disord. 1994, 29, 85-96. [CrossRef]

10. Amick, B.C., III; Kawachi, I.; Coakley, E.H.; Lerner, D.; Levine, S.; Colditz, G.A. Relationship of job strain and iso-strain to health status in a cohort of women in the United States. Scand. J. Work Environ. Health 1998, 24, 54-61. [CrossRef]

11. Schmidt, P.J.; Murphy, J.H.; Haq, N.; Rubinow, D.R.; Danaceau, M.A. Stressful life events, personal losses, and perimenopause-related depression. Arch. Womens Ment. Health 2004, 7, 19-26. [CrossRef] [PubMed]

12. Caspi, A.; Sugden, K.; Moffitt, T.E.; Taylor, A.; Craig, I.W.; Harrington, H.; McClay, J.; Martin, J.; Braithwaite, A.; Poulton, R. Influence of life stress on depression: Moderation by a polymorphism in the 5-HTT gene. Science 2003, 301, 386-389. [CrossRef] [PubMed]

13. Woods, N.F.; Mariella, A.; Mitchell, E.S. Depressed mood symptoms during the menopausal transition: Observations from the Seattle Midlife Women's Health Study. Climacteric 2006, 93, 195-203. [CrossRef] [PubMed]

14. Mulhall, S.; Andel, R.; Anstey, K.J. Variation in symptoms of depression and anxiety in midlife women by menopausal status. Maturitas 2018, 108, 7-12. [CrossRef]

15. Mühlberg, W.; Sieber, C. Sarcopenia and frailty in geriatric patients: Implications for training and prevention. Z. Gerontol. Geriatr. 2004, 37, 2-8. [CrossRef] [PubMed]

16. Verma, S.K.; Willetts, J.L.; Corns, H.L.; Marucci-Wellman, H.R.; Lombardi, D.A.; Courtney, T.K. Falls and fall-related injuries among community-dwelling adults in the United States. PLoS ONE 2016, 11, e0150939. [CrossRef] [PubMed]

17. Granacher, U.; Muehlbaue, T.; Zahner, L.; Gollhofer, A.; Kressig, R.W. Comparison of traditional and recent approaches in the promotion of balance and strength in older adults. Sports Med. 2011,41,377-400. [CrossRef]

18. Menant, J.C.; Schoene, D.; Sarofim, M.; Lord, S.R. Single and dual task tests of gait speed are equivalent in the prediction of falls in older people: A systematic review and meta-analysis. Ageing Res. Rev. 2014, 16, 83-104. [CrossRef]

19. Kyrdalen, I.L.; Thingstad, P.; Sandvik, L.; Ormstad, H. Associations between gait speed and well-known fall risk factors among community-dwelling older adults. Physiother. Res. Int. 2019, 24, e1743. [CrossRef]

20. Lopes, K.T.; Costa, D.F.; Santos, L.F.; Castro, D.P.; Bastone, A.C. Prevalence of fear of falling among a population of older adults and its correlation with mobility, dynamic balance, risk and history of falls. Rev. Bras. Fisioter. 2009, 13, 223-229. [CrossRef]

21. World Health Organization. Obesity: Preventing and Management of the Global Epidemic. Report of the WHO Consultation. Technical Report Series. No. 894; World Health Organization: Geneva, Switzerland, 2000.

22. Buysse, D.J.; Reynolds, C.F.; Monk, T.H.; Berman, S.R.; Kupfer, D.J. The Pittsburgh Sleep Quality Index: A new instrument for psychiatric practice and research. Psychiatry Res. 1989, 28, 193-213. [CrossRef]

23. Hita-Contreras, F.; Martínez-López, E.; Latorre-Román, P.A.; Garrido, F.; Santos, M.A.; Martínez-Amat, A. Reliability and validity of the Spanish version of the Pittsburgh Sleep Quality Index (PSQI) in patients with fibromyalgia. Rheumatol. Int. 2014, 34, 929-936. [CrossRef] [PubMed]

24. Doi, Y.; Minowa, M.; Uchiyama, M.; Okawa, M.; Kim, K.; Shibui, K.; Kamei, Y. Psychometric assessment of subjective sleep quality using the Japanese version of the Pittsburgh Sleep Quality Index (PSQI-J) in psychiatric disordered and control subjects. Psychiatr. Res. 2000, 97, 165-172. [CrossRef]

25. Zigmond, A.S.; Snaith, R.P. The hospital anxiety and depression scale. Acta. Psychiatr. Scand. 1983, 67, 361-370. [CrossRef] 
26. Herrero, M.J.; Blanch, J.; Peri, J.M.; De Pablo, J.; Pintor, L.; Bulbena, A. A validation study of the hospital anxiety and depression scale (HADS) in a Spanish population. Gen. Hosp. Psychiatr. 2003, 25, 277-283. [CrossRef]

27. Beekman, E.; Verhagen, A. Clinimetrics: Hospital anxiety and depression scale. J. Physiother. 2018, 64, 198. [CrossRef]

28. Pisciottano, M.V.C.; Pinto, S.S.; Szejnfeld, V.L.; de Moura Castro, C.H. The relationship between lean mass, muscle strength and physical ability in independent healthy elderly women from the community. J. Nutr. Health Aging 2014, 18, 554-558. [CrossRef]

29. Clark, S.; Parisi, J.; Kuo, J.; Carlson, M.C. Physical activity is associated with reduced risk of executive function impairment in older women. J. Aging Health 2016, 28, 726-739. [CrossRef]

30. Piccoli, A.; Codognotto, M.; Piasentin, P.; Naso, A. Combined evaluation of nutrition and hydration in dialysis patients with bioelectrical impedance vector analysis (BIVA). Clin. Nutr. 2014, 33, 673-677. [CrossRef]

31. Podsiadlo, D.; Richardson, S. The timed "Up \& Go": A test of basic functional mobility for frail elderly persons. Am. Geriatr. Soc. 1991, 39, 142-148.

32. Chauhan, K.; Sheth, M.; Vyas, N. Comparison of the effect of chair rising exercise and one-leg standing exercise on dynamic body balance in geriatrics: An experimental study. Indian. J. Phys. Ther. 2014, 2, 22-26.

33. Carter, V.; Jain, T.; James, J.; Cornwall, M.; Aldrich, A.; de Heer, H.D. The 3-m backwards walk and retrospective falls: Diagnostic accuracy of a novel clinical measure. J. Geriatr. Phys. Ther. 2019, 42, 249-255. [CrossRef] [PubMed]

34. Concato, J.; Peduzzi, P.; Holford, T.R.; Feinstein, A.R. Importance of events per independent variable in proportional hazards analysis. I. Background, goals, and general strategy. J. Clin. Epidemiol. 1995, 48, 1495-1501. [CrossRef]

35. Cohen, J.A. A power primer. Psychol. Bull. 1992, 112, 155-159. [CrossRef] [PubMed]

36. Jiménez-García, J.D.; Martínez-Amat, A.; De la Torre-Cruz, M.J.; Fábrega-Cuadros, R.; Cruz-Díaz, D.; Aibar-Almazán, A.; Achalandabaso-Ochoa, A.; Hita-Contreras, F. Suspension Training HIIT improves gait speed, strength and quality of life in older adults. Int. J. Sports Med. 2019, 40, 116-124. [CrossRef]

37. Jiménez-García, J.D.; Hita-Contreras, F.; de la Torre-Cruz, M.; Fábrega-Cuadros, R.; Aibar-Almazán, A.; Cruz-Díaz, D.; Martínez-Amat, A. Risk of falls in healthy older adults: Benefits of high-intensity interval training using lower body suspension exercises. J. Aging Physical. Act. 2019, 27, 325-333. [CrossRef]

38. Aibar-Almazán, A.; Hita-Contreras, F.; Cruz-Díaz, D.; de la Torre-Cruz, M.; Jiménez-García, J.D.; Martínez-Amat, A. Effects of Pilates training on sleep quality, anxiety, depression and fatigue in postmenopausal women: A randomized controlled trial. Maturitas 2019, 124, 62-67. [CrossRef]

39. Pace-Schott, E.F.; Spencer, R.M. Age-Related changes in the cognitive function of sleep. Prog. Brain Res. 2011, 191, 75-89.

40. Eysenck, M.W.; Derakshan, N.; Santos, R.; Calvo, M.G. Anxiety and cognitive performance: Attentional control theory. Emotion 2007, 7, 336. [CrossRef]

41. Kurose, S.; Miyauchi, T.; Yamashita, R.; Tamaki, S.; Imai, M.; Nakashima, Y.; Umeda, Y.; Sato, S.; Kimura, Y.; Masuda, I. Association of locomotive activity with sleep latency and cognitive function of elderly patients with cardiovascular disease in the maintenance phase of cardiac rehabilitation. J. Cardiol. 2019, 73, 530-535. [CrossRef]

42. Del Brutto, O.H.; Mera, R.M.; Sedler, M.J.; Zambrano, M.; Nieves, J.L.; Cagino, K.; Fanning, K.D.; Milla-Martínez, M.F.; Castillo, P.R. The effect of age in the association between frailty and poor sleep quality: A population-based study in community-dwellers (The Atahualpa Project). J. Med. Dir. Assoc. 2016, 17, 269-271. [CrossRef] [PubMed]

43. Fu, L.; Jia, L.; Zhang, W.; Han, P.; Kang, L.; Ma, Y.; Yu, H.; Zhai, T.; Chen, X.; Guo, Q. The association between sleep duration and physical performance in Chinese community-dwelling elderly. PLoS ONE 2017, 12, e0174832. [CrossRef] [PubMed]

44. Roepke, S.K.; Ancoli-Israel, S. Sleep disorders in the elderly. Indian J. Med. Res. 2010, 131, 302. [PubMed]

45. Hill, E.L.; Cumming, R.G.; Lewis, R.; Carrington, S.; Couteur, D.G.L. Sleep disturbances and falls in older people. J. Gerontol. A Biol. Sci. Med. Sci. 2007, 62, 62-66. [CrossRef]

46. Cruz-Jentoft, A.J.; Bahat, G.; Bauer, J.; Boirie, Y.; Bruyère, O.; Cederholm, T.; Cooper, C.; Landi, F.; Rolland, Y.; Sayer, A.A.; et al. Sarcopenia: Revised European consensus on definition and diagnosis. Age Ageing 2019, 48, 16-31. [CrossRef] 
47. Figueiredo, D.; Neves, M. Falls Efficacy Scale-International: Exploring psychometric properties with adult day care users. Arch. Gerontol. Geriatr. 2018, 79, 145-150. [CrossRef]

48. Herman, T.; Giladi, N.; Hausdorff, J.M. Properties of the 'timed up and go'test: More than meets the eye. Gerontology 2011, 57, 203-210. [CrossRef]

49. Carral, J.M.C.; Ayan, C.; Sturzinger, L.; Gonzalez, G. Relationships between body mass index and static and dynamic balance in active and inactive older adults. J. Geriatr. Phys. Ther. 2019, 42, E85-E90. [CrossRef]

50. Lin, C.H.; Liao, K.C.; Pu, S.J.; Chen, Y.C.; Liu, M.S. Associated factors for falls among the community-dwelling older people assessed by annual geriatric health examinations. PLoS ONE 2011, 6, e18976. [CrossRef]

51. Follis, S.; Cook, A.; Bea, J.W.; Going, S.B.; Laddu, D.; Cauley, J.A.; Shadyab, A.H.; Stefanick, M.L.; Chen, Z. Association between sarcopenic obesity and falls in a multiethnic cohort of postmenopausal women. J. Am. Geriatr. Soc. 2018, 66, 2314-2320. [CrossRef]

(C) 2020 by the authors. Licensee MDPI, Basel, Switzerland. This article is an open access article distributed under the terms and conditions of the Creative Commons Attribution (CC BY) license (http://creativecommons.org/licenses/by/4.0/). 